\title{
Effects of curcumin on retinal oxidative stress and inflammation in diabetes
}

\author{
Renu A Kowluru* and Mamta Kanwar
}

\author{
Address: Kresge Eye Institute, Wayne State University, Detroit, MI, USA \\ Email: Renu A Kowluru* - rkowluru@med.wayne.edu; Mamta Kanwar - mkanwar@med.wayne.edu \\ * Corresponding author
}

Published: 16 April 2007

Nutrition \& Metabolism 2007, 4:8 doi:10.1 186/1743-7075-4-8
Received: 25 January 2007

Accepted: 16 April 2007

This article is available from: http://www.nutritionandmetabolism.com/content/4/1/8

(C) 2007 Kowluru and Kanwar; licensee BioMed Central Ltd.

This is an Open Access article distributed under the terms of the Creative Commons Attribution License (http://creativecommons.org/licenses/by/2.0), which permits unrestricted use, distribution, and reproduction in any medium, provided the original work is properly cited.

\begin{abstract}
Background: Oxidative stress and inflammation are implicated in the pathogenesis of retinopathy in diabetes. The aim of this study is to examine the effect of curcumin, a polyphenol with antioxidant and anti-inflammatory properties, on diabetes-induced oxidative stress and inflammation in the retina of rats.
\end{abstract}

Methods: A group of streptozotocin-induced diabetic rats received powdered diet supplemented with $0.05 \%$ curcumin $(\mathrm{w} / \mathrm{w})$, and another group received diet without curcumin. The diets were initiated soon after induction of diabetes, and the rats were sacrificed 6 weeks after induction of diabetes. The retina was used to quantify oxidative stress and pro-inflammatory markers.

Results: Antioxidant capacity and the levels of intracellular antioxidant, GSH (reduced form of glutathione) levels were decreased by about $30-35 \%$, and oxidatively modified DNA (8-OHdG) and nitrotyrosine were increased by $60-70 \%$ in the retina of diabetic rats. The levels of interleukin-I $\beta$ (IL-I $\beta$ ) and vascular endothelial growth factor (VEGF) were elevated by $30 \%$ and I I0\% respectively, and the nuclear transcription factor (NF-kB) was activated by 2 fold. Curcumin administration prevented diabetes-induced decrease in the antioxidant capacity, and increase in 8-OHdG and nitrotyrosine; however, it had only partial beneficial effect on retinal GSH. Curcumin also inhibited diabetes-induced elevation in the levels of IL-I $\beta$, VEGF and NF-kB. The effects of curcumin were achieved without amelioration of the severity of hyperglycemia.

Conclusion: Thus, the beneficial effects of curcumin on the metabolic abnormalities postulated to be important in the development of diabetic retinopathy suggest that curcumin could have potential benefits in inhibiting the development of retinopathy in diabetic patients.

\section{Background}

Diabetic retinopathy is the main cause of acquired blindness in working adults. Abnormalities in retinal metabolism, including elevated polyol pathway activity, increased nonenzymatic glycation and advanced glycation end products, oxidative stress, protein kinase $\mathrm{C}$ (PKC) activity [1-5], evidently contribute to the develop- ment of retinopathy, but the exact mechanism is still elusive. In diabetes the retina experiences increased oxidative stress [4,6-8], and reactive oxygen species (ROS) are considered as a causal link between elevated glucose and the metabolic abnormalities important in the development of diabetic complications [9]. However, the mechanism by 
which oxidative stress can contribute to the development of diabetic retinopathy remains to be elucidated.

Recent studies have compared the development of diabetic retinopathy to the low-level chronic inflammatory disease; the retinal capillaries become nonperfused and ischemic, and the number of platelet-fibrin thrombi increases in diabetes [10]. The levels of pro-inflammatory cytokines are increased in the retina and vitreous in diabetes $[11,12]$. We have shown that intravitreal injection of interleukin-1 $\beta$ (IL-1 $\beta$ ) to the normal rats increases retinal capillary cell apoptosis and histopathology; and these IL$1 \beta$-induced changes in the retinal capillaries of normal rats are similar to those observed in diabetes [13]. Further, IL-1 $\beta$ is shown to increase the expression of vascular endothelial growth factor (VEGF) in retinal endothelial cells [14], and VEGF is implicated in the development of diabetic retinopathy [15].

Curcumin, a bis- $\alpha, \beta$-unsaturated $\beta$-diketone (Figure 1), possesses diverse antioxidant and anti-inflammatory properties $[16,17]$. It significantly decreases lipid peroxidation, increases intracellular antioxidant, GSH, regulates antioxidant enzymes, and scavenges hyperglycemiainduced ROS $[18,19]$. In addition, curcumin is shown to inhibit the pro-inflammatory transcriptional factor, NF$k \mathrm{~B}$, and prevent up-regulation of VEGF mRNA and microvascular angiogenesis [20]. However, the beneficial effect of curcumin on diabetic retinopathy remains to be explored.

In the present study we have investigated the effect of administration of curcumin on oxidative stress and inflammatory markers in the retina of diabetes. The total antioxidant capacity, and the levels of GSH, oxidatively modified DNA (8-OHdG), nitrotyrosine, IL-1 $\beta$, NF- $k$ B and VEGF were quantified in the retina of diabetic rats that received diets supplemented with or without curcumin for 6 weeks, and for comparison, in the retina of agematched normal control rats. The results presented show that curcumin administration for 6 weeks prevents diabetes-induced increase in retinal oxidative stress and inhibits the levels of pro-inflammatory markers.

\section{Methods}

\section{Rats}

Lewis rats (200 to $220 \mathrm{~g}$, male) were made diabetic with streptozotocin ( $55 \mathrm{mg} / \mathrm{kg}$ body weight). Insulin was administered to diabetic rats to allow slow weight gain while maintaining hyperglycemia (blood glucose levels of 20-25 mM). Age-matched normal rats served as control. Diabetic rats were divided into 2 groups: the rats in group 1 received powdered diet (Purina 5001) without any supplementation, and group 2 received diet supplemented with curcumin $(0.5 \mathrm{~g} / \mathrm{kg}$ diet $)$; these diets were initiated soon after establishment of diabetes (3-4 days after administration of streptozotocin). Each group had 8-12 rats, and the entire rat colony received fresh powdered diet weekly. The rats were weighed two times a week and their food consumption was measured once every week. After 6 weeks of diabetes the rats were euthanized by an overdose of pentobarbital, the eyes were removed, and retina was isolated and frozen immediately in liquid nitrogen for biochemical measurements. Treatment of the animals conformed to the National Institutes of Health Principles of Laboratory Animal Care, the Association for Research in Vision and Ophthalmology Resolution on the Use of Animals in Research, and the Institutional guidelines.

\section{Oxidative stress}

The total antioxidant capacity of the retina was measured using a kit from Cayman Chemical (Ann Arbor, MI) according to the method recently used by us [21]. The assay is based on the ability of the sample to inhibit oxidation of 2,2'-Azino-di- [3-ethylbenzthiazoline sulfonate $]^{+}$(ABTS) by metmyoglobin; the antioxidants in the sample cause the decrease in absorbance at $750 \mathrm{~nm}$, and that represents the amount of ABTS+ produced. Each sample was measured in duplicate.

The levels of 8-OHdG were quantified by competitive ELISA (Oxis Research Laboratories, OR) using 15-20 $\mu \mathrm{g}$ DNA purified from the retina that has been digested with DNAse, as described previously [22].

GSH was measured using the Glutathione Assay Kit from

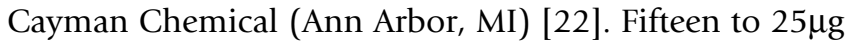
retinal protein was deproteinized using phosphoric acid, and the supernatant was used to measure the amount of 5-thio-2-nitrobenzoic acid.

Peroxynitrite is formed by the reaction between superoxide and nitric oxide, and nitrotyrosine is a measure of peroxynitrite. Nitrotyrosine levels were quantified by enzyme immunoassay using a Nitrotyrosine-EIA kit from Oxis Research, Portland, OR, as previously used by us [22]. The sensitivity of the assay was as low as 0.05 pmoles of nitrotyrosine.

\section{Inflammation}

The amount of IL- $1 \beta$ was quantified in the retina by ELISA (R\&D Systems, Minneapolis, MN) as previously described by us [12]. Unbound substances were removed by incubating the samples with rat polyclonal antibody in precoated microplates. The results are reported as pg of IL-1 $\beta /$ mg retina protein in each sample.

VEGF levels were quantified in the retina by an ELISA method using a kit from R\&D Systems, MN. The standard solution or the samples were added in a 96-well plate that 


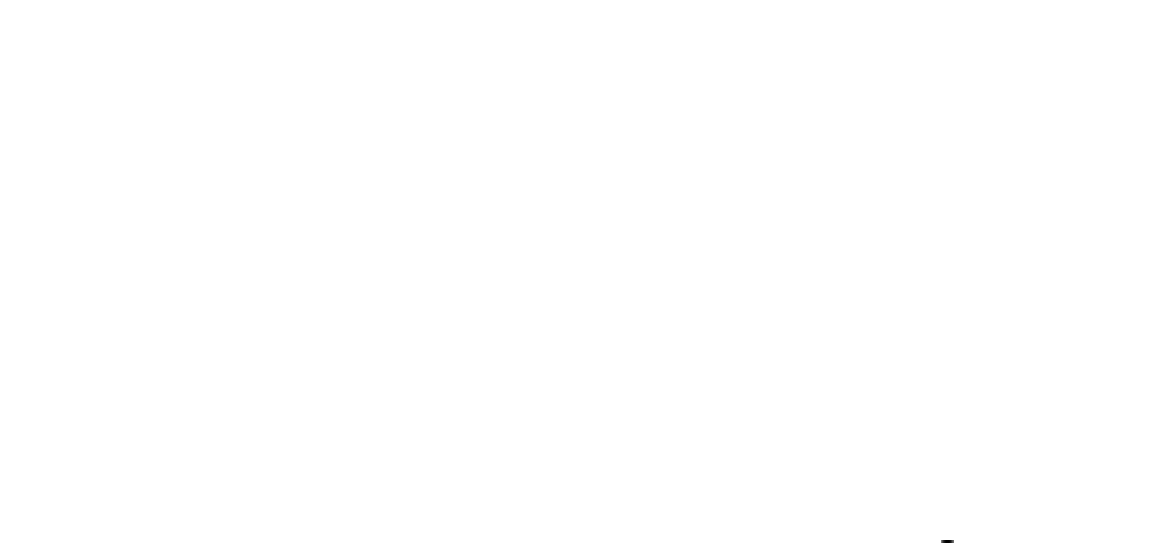

Figure I

Structure of curcumin. I,7-bis (4-hydroxy-3-methoxy-phenyl) hepta-I, 6-diene-3, 5-dione).

was pre-coated with a monoclonal antibody. The samples were incubated for 2 hours, and after washing the plate the samples were incubated with rat VEGF-conjugate. The assay was sensitive to the concentration of VEGF as low as $15 \mathrm{ng} / \mathrm{ml}$.

The activation of the transcription factor that is under the control of IL- $1 \beta, N F-k B$, was determined by ELISA that is based on the principle that only the active form of NF- $k \mathrm{~B}$ in the sample binds to oligonucleotide containing NF- $k \mathrm{~B}$ consensus site (5,-GGGACTTTCC-3'), which is immobilized on the microtiter plate. Eight- $10 \mu \mathrm{g}$ of retina protein was sufficient to provide reliable readings [22].

Protein expressions of IL-1 $\beta$, VEGF and p65 subunit of $\mathrm{NF}-k \mathrm{~B}$ were determined by western blot using polyclonal antibodies against IL-1 $\beta$, VEGF and p65 respectively. The membranes were developed using ECL-Plus western blotting reagents, and $\beta$-actin was used as a house-keeping protein.

\section{Statistical analysis}

Data are reported as mean \pm SD. The results were analyzed using one-way ANOVA followed by Fischer's test. Similar conclusions were reached by nonparametric Kruskal-Wallis, test followed by Mann-Whitney test for multiple group comparison.

\section{Results}

\section{Oxidative stress}

Oxidative stress, as determined by the overall antioxidant capacity, concentration of the intracellular antioxidant and the levels of oxidatively modified DNA remained elevated in the retina of rats diabetic for 6 weeks. The antioxidant capacity of the retina and GSH levels were decreased by about 30-35\% (Figure 2), and 8-OHdG levels were ele- vated by over $70 \%$ (Figure 3 ) in diabetes compared to the age-matched normal control rats.

Administration of curcumin prevented diabetes-induced decrease in the total antioxidant capacity of the retina; the values obtained from normal control rats and in curcumin-treated diabetic rats were similar (Figure 2a). However, diabetes-induced decrease in retinal GSH was partially inhibited by curcumin administration; although GSH levels were lower in the retina of curcumin-treated diabetic rats compared to the normal control rats, these values were significantly higher compared to the diabetes group ( $P=0.04$; Figure $2 \mathrm{~b})$. In the same rats, curcumin administration had significant beneficial effect on oxidative modification of retinal DNA; 8-OHdG values in curcumin-treated diabetic group and normal control group were not different from each other $(P=0.32$ compared to normal, Figure 3).

Six weeks of diabetes increased nitrotyrosine levels in the retina by about $60 \%$ compared to the values obtained from normal control rats (Figure 4). Curcumin supplementation in diabetic rats prevented increase in retinal nitrotyrosine levels; the values in the curcumin-treated diabetic rats were significantly lower compared to diabetic rats without curcumin $(\mathrm{P}<0.05$, Figure 4$)$.

\section{Inflammation}

The concentration of the inflammatory cytokine IL-1 $\beta$ and its protein expression were elevated by $30 \%$ in the retina of diabetic rats (Figure 5). In the same retina, the transcription factor that is under the control of IL- $1 \beta, N F-k B$, was also activated by about 2 fold (Figure 6). Administration of curcumin inhibited diabetes-induced increase in inflammatory markers in the retina; the levels of IL-1 $\beta$ were significantly decreased in diabetic rats receiving cur- 

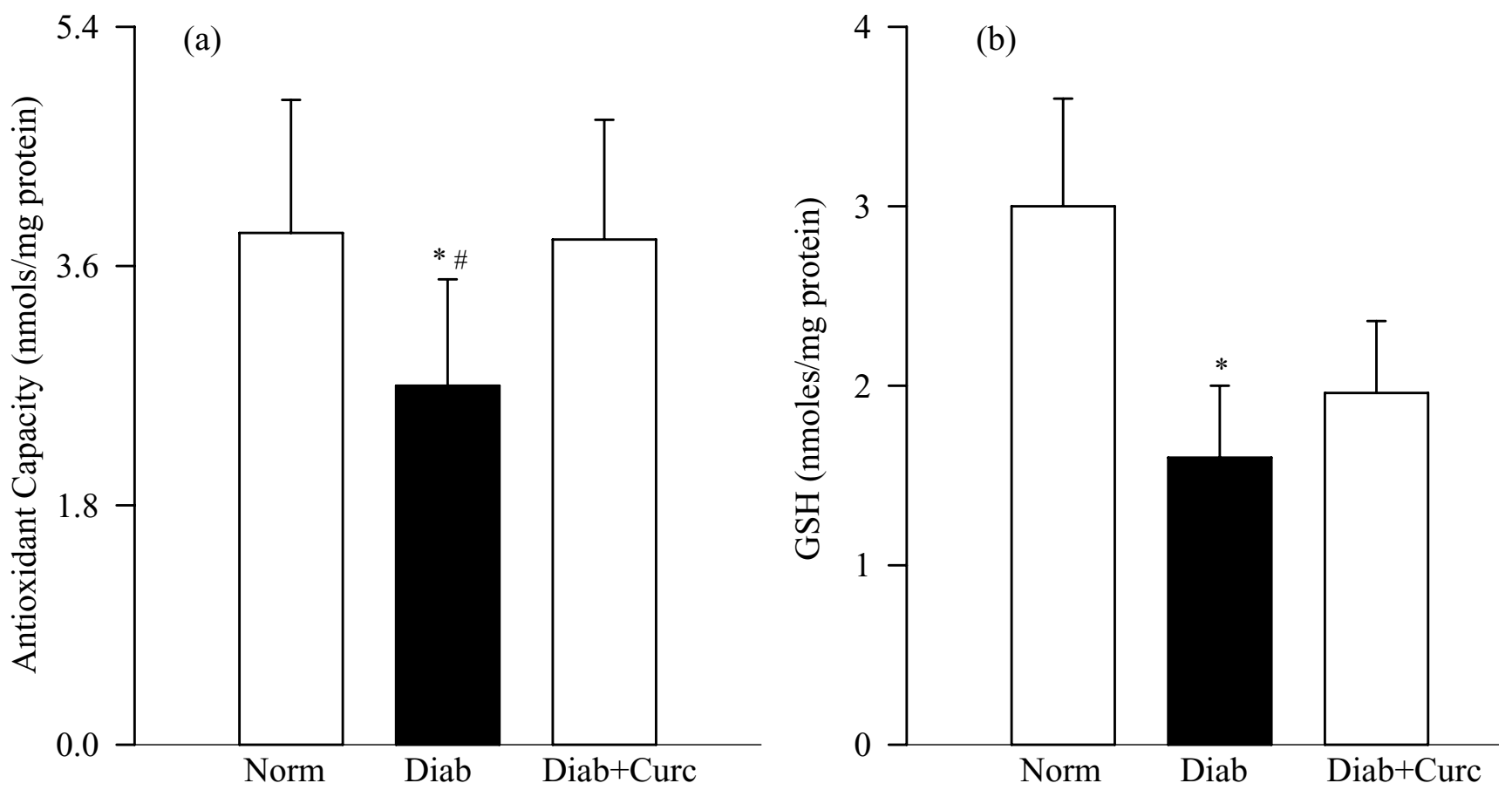

Figure 2

Effect of curcumin on diabetes-induced oxidative stress in the retina. (a) Total antioxidant capacity of the retina was quantified by measuring the ability of the retina to inhibit oxidation of ABTS by metmyoglobin using 5-10 $\mu \mathrm{g}$ retina protein. (b) Retinal GSH was estimated in the deproteinizing retinal homogenate using a kit from Cayman Chemical (MI). Each sample was measured in duplicate, and the values are represented as mean \pm SD of 7-8 rats in diabetes group and 7-9 rats each on normal and diabetes + curcumin groups. Norm $=$ normal; Diab $=$ Diabetes; Diab + Curc $=$ Diabetes + curcumin treated rats. $* P<0.05$ compared to normal, \#P < compared to diabetes + curcumin.

cumin $(\mathrm{P}<0.05)$, and in the same retina the activation of NF- $k$ B was also diminished.

The endothelial growth factor, VEGF, was elevated by over 2 fold in the retina obtained from diabetic rats (Figure 7). Supplementation with curcumin prevented diabetesinduced increase in VEGF; the values obtained from normal control and diabetes + curcumin rats were not significantly different from each other.

Similar beneficial effects of curcumin supplementation were obtained on diabetes-induced increased protein expression of retinal IL-1 $\beta$, p65 subunit of NF- $k$ B and VEGF (data not shown).

\section{Severity of hyperglycemia}

The severity of hyperglycemia, as measured by body weight of the rats and their blood glucose and 24 hour urine volumes, was strikingly increased in the diabetes group compared with the normal control group. Curcumin did not ameliorate the severity of hyperglycemia in diabetic rats; the body weight, blood glucose and urine volumes were comparable between the two diabetic groups (diabetes and diabetes + curcumin), and these parameters were significantly different $(P<0.001)$ from the normal control group (Table 1). The average curcumin consumption in diabetic rats, calculated from the daily average food intake, was about $16 \mathrm{mg} /$ day.

\section{Discussion}

This is the first report showing that curcumin, a polyphenol, has beneficial effects on retinal metabolic abnormalities, including oxidative stress and inflammation, which are considered to be important in the development of retinopathy in diabetes. These results raise the possibility that curcumin may help inhibit the development of diabetic retinopathy.

The antioxidant capacity, a measure of the total protective antioxidant mechanisms (both for preventing the production of free radicals and for repairing oxidative damage) [23], of curcumin has been considered to be mediated via its beneficial effects on the antioxidant defense system, the scavenging of free radicals and/or via preventing lipid peroxidation and it is at least 10 times more active as an antioxidant than vitamin E [24]. Diabetes decreases the 


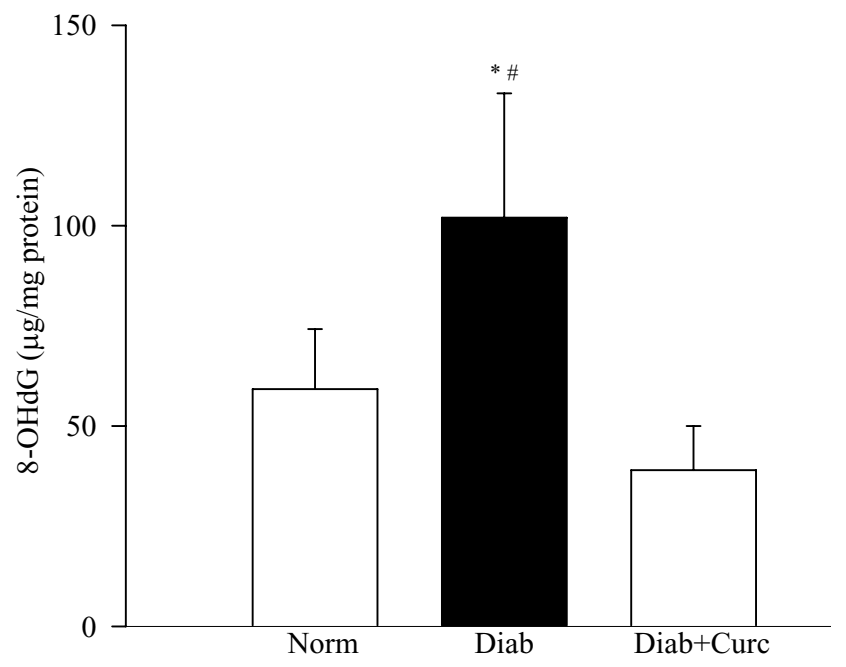

Figure 3

Effect of curcumin on oxidatively modified DNA levels in the retina. 8-OHdG levels were measured in the retina using an ELISA kit from Oxis Research. Values are represented as mean \pm SD of 6-8 rats in each group. *P < 0.05 compared to normal, and \#P $<0.05$ compared to diabetes + curcumin.

total antioxidant capacity of the retina [21], and here we provide data showing that the administration of curcumin can prevent diabetes-induced decrease in the total antioxi-

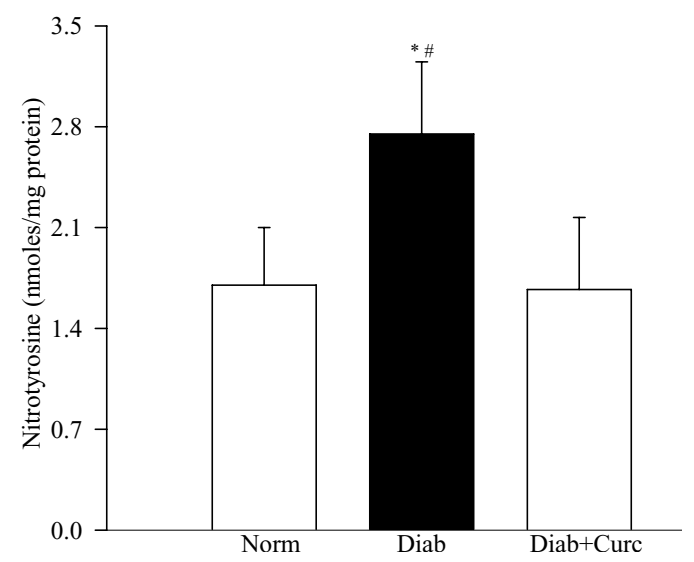

\section{Figure 4}

Effect of curcumin on retinal nitrotyrosine levels in diabetes. Nitrotyrosine-EIA kit was used to quantify nitrotyrosine in the retina. Each sample was measured in duplicate. The figure represents mean \pm SD of 6 rats each in normal and diabetes + curcumin groups and 7 rats in diabetes group. $* \mathrm{P}<0.05$ compared to normal, \#P $<$ compared to diabetes + curcumin.

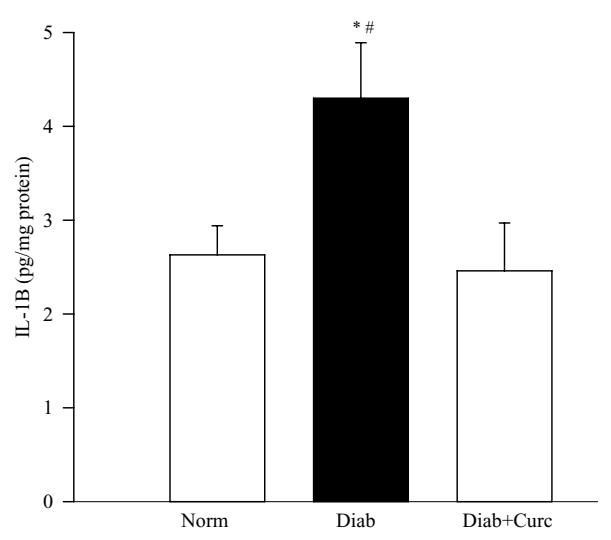

\section{Figure 5}

Effect of curcumin on diabetes-induced increase in retinal IL-I $\beta$ levels. An ELISA kit from R\&D Systems, Minneapolis, $M N$, was used to quantify IL-I $\beta$ in the retina. Each sample was run in duplicate to ensure reproducibility of the data. IL- I $\beta$ values (pg IL-I $\beta / \mathrm{mg}$ protein) are mean \pm SD obtained from 8 rats each in diabetes and diabetes + curcumin groups and 6 rats in normal group. ${ }^{*} \mathrm{P}<0.05$ and $\# \mathrm{P}<$ 0.05 compared to normal and diabetes + curcumin groups respectively.

dant capacity of the retina. This suggests that curcumin has a potential to inhibit overall oxidative damage experienced by the retina in diabetes.

Administration of curcumin decreases diabetes-induced increase in retinal 8-OHdG levels. In support, recent studies by Farhangkhoee et al [25] have shown that curcumin treatment decreases diabetes-induced increased 8-OHdG immunoreactivity in the heart. 8 -OHdG has been implicated in the pathogenesis of diabetic retinopathy; inhibition of increased retinal capillary cell apoptosis and the development of diabetic retinopathy by lipoic acid are considered to be mediated via inhibition of increased retinal 8-OHdG levels [25]. The role of increased retinal 8OHdG levels in the pathogenesis of diabetic retinopathy is further strengthened by the studies showing that overexpression of mitochondrial superoxide dismutase (MnSOD) inhibits increase in retinal 8-OHdG levels $[8,21]$. Inhibition of diabetes-induced elevated retinal 8OHdG levels by curcumin suggests that curcumin could inhibit the development of diabetic retinopathy, in part, via inhibiting accumulation of oxidized DNA in the retina.

GSH, an intracellular antioxidant, is important in antioxidant defense, nutrient metabolism, and regulation of cellular events, including gene expression, apoptosis and 


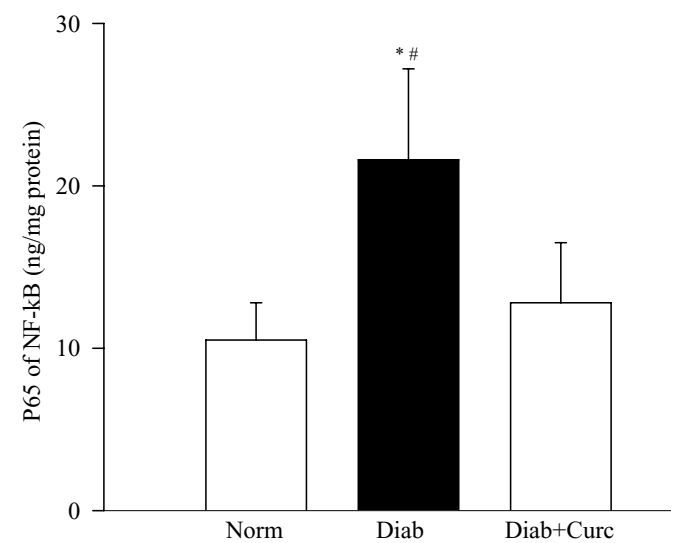

\section{Figure 6}

Effect of curcumin on NF-kB activation. NF-kB activation was determined in the retinal homogenate by ELISA method (kit from Active Motif.) using antibody specific for p65 subunit of NF-kB. Secondary antibody conjugated to horseradish peroxidase was used to quantify the activated form spectrophotometrically. The figure represents mean \pm SD of 5-6 rats each in of the 3 groups. *P $<0.05$ compared with normal or diabetes + curcumin groups.

cytokine production [26]. Decreased GSH levels are observed in the retina in diabetes, and antioxidants and

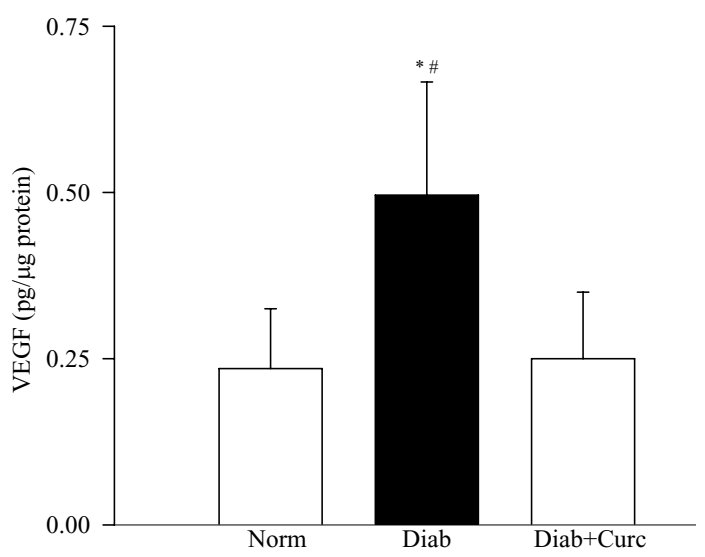

\section{Figure 7}

VEGF levels in curcumin-treated rats. VEGF concentrations were measured in the retina of rats in normal, diabetes and diabetes + curcumin groups using an ELISA kit from R\&D Systems. Results are presented as mean \pm SD of 6 rats in diabetes and 7 rats each in normal and diabetes + curcumin groups. $* \mathrm{P}<0.05$ compared to normal, and \#P $<0.05$ compared to diabetes + curcumin.
MnSOD overexpression inhibit such diabetes-induced decreases in retinal GSH $[22,27]$. Here, we provide data demonstrating that curcumin administration has partial beneficial effect on diabetes-induced decrease in retinal GSH; the GSH levels in curcumin-treated diabetic rats remained significantly lower than those in the normal control rats, but were significantly higher than diabetic rats. Others have shown that curcumin administration increases defense against oxidative stress in the liver via a GSH-linked mechanism [28]. Our failure to achieve complete restoration of retinal GSH levels could be that higher levels of curcumin may be essential to regulate retinal GSH metabolism in diabetes, and the rats in our experiment were not able to achieve such levels. Or, there could be compartmentalization of GSH in the retina, and levels could possibly be normalized in the cells associated with the development of diabetic retinopathy.

The therapies that inhibit diabetes-induced nitrotyrosine accumulation in the retina are shown to inhibit diabetic retinopathy $[22,29,30]$. Here we demonstrate that curcumin can prevent diabetes-induced increase in nitrotyrosine levels in the retina. In support, curcumin has been reported to inhibit diabetes-induced increased nitrotyrosine immunostaining in the heart [25], and also is postulated to exert its neuroprotective effects and prevent alcohol-induced liver damage via regulating peroxynitrite levels [31,32].

Diabetic retinopathy shares similarities with low level chronic inflammatory disease, and subclinical inflammation is considered to play a role in the vascular lesions characteristic of diabetic retinopathy [33]. The levels of cytokines, including IL- $1 \beta$, IL- 6 and IL- 8 , are increased in the vitreous of patients with proliferative diabetic retinopathy and in the retina from diabetic rats and mice $[11,22,34]$. The capillaries become nonperfused and ischemic and the number of platelet-fibrin thrombi increases; these pro-inflammatory changes and leukostasis constitute as some of the earliest changes observed in the retina of diabetic animals [10]. ROS are considered as strong stimuli for the release of cytokines, and IL-1 $\beta$ itself can trigger signaling cascades resulting in excessive ROS [14]. Our data demonstrate that curcumin, a compound with both anti-inflammatory and antioxidant properties, prevents diabetes-induced increase in IL-1 $\beta$. This suggests that curcumin could inhibit the development of diabetic retinopathy by inhibiting both, proinflammatory cytokines and oxidative stress.

IL-1 $\beta$ induces the expression of various genes whose promoters are regulated through complex interactions with NF- $k$ B [35]. NF- $k$ B, a redox sensitive factor and a key regulator of antioxidant enzymes, can initiate transcription of many genes involved in apoptosis [36], and curcumin 
Table I: Effect of curcumin on the severity of hyperglycemia in rats

\begin{tabular}{lcccc}
\hline & Body weight $(\mathrm{g})$ & Food Consumption $(\mathrm{g} / \mathrm{day})$ & Blood glucose $(\mathrm{mg} / \mathrm{dl})$ & Urine volume $(\mathrm{ml} / 24 \mathrm{hour})$ \\
\hline Normal & $255 \pm 17$ & $24.7 \pm 6.0$ & $11 \mathrm{II} \pm 18$ & $8 \pm 3$ \\
Diabetes & $216 \pm 12^{*}$ & $36.6 \pm 6.1^{*}$ & $469 \pm 81^{*}$ & $53 \pm 18^{*}$ \\
Diabetes + Curcumin & $200 \pm 30^{*}$ & $32.2 \pm 3.2^{*}$ & $451 \pm 123^{* \#}$ & $55 \pm 14^{* \#}$ \\
\hline
\end{tabular}

Twenty four hour urine excretion (measured over 3 consecutive days) was quantified at 6 weeks of diabetes. Values are mean \pm SD of 8 rats each in normal group and diabetes + curcumin group and 7 rats in diabetes group. $* P<0.02$ compared to normal, \#P $>0.02$ compared to diabetes.

is a potent blocker of NF-kB activation [37]. We have shown that NF- $k$ B is activated in the retina and its capillary cells in diabetes, and its activation is an early event in the development of retinopathy that is sustained when retinal capillary cell death is accelerating, and histopathology is developing [29]. In the pathogenesis of diabetic retinopathy activation of NF- $k \mathrm{~B}$ is reported to trigger a developing pro-apoptotic program in retinal pericytes [38], and accelerated apoptosis can predict the development of retinopathy in diabetes [39]. Here we provide clear evidence that curcumin administration inhibits the activation of NF- $k \mathrm{~B}$, accumulation of $8-\mathrm{OHdG}$ and nitrotyrosine in the retina in diabetes. This raises a possibility that curcumin can inhibit apoptosis of retinal capillary cells, a predictor of the development of diabetic retinopathy [39].

Diabetic retinopathy is accompanied by elevation in various angiogenic factors, and VEGF, a hypoxia-induced growth factor, is considered to play a pivotal role in the increased permeability and angiogenesis seen in diabetic retinopathy [15]. Oxidative stress is considered to regulate diabetes-induced retinal VEGF levels [40]. Our data clearly show that curcumin administration inhibits increased VEGF levels in the retina. In agreement, others have shown that curcumin can abolish IL-18 induced increase in VEGF production [41].

The beneficial effects of curcumin observed in the present study were achieved without amelioration of the severity of hyperglycemia in diabetic rats; the blood glucose, urine volume and body weights were similar in diabetic rats and diabetes + curcumin rats.

Curcumin is shown to be safely tolerated, clinical trials using up to $8000 \mathrm{mg}$ curcumin per day for 3 months have shown no toxicity to curcumin [42]. Based on the food consumption, the rats in our experiment consumed about $16 \mathrm{mg}$ curcumin per day (about $80 \mathrm{mg} / \mathrm{kgBW}$ ), and this concentration is within the range of the concentration used for clinical trials. However, curcumin has poor oral bioavailability [43] that could limit its full potential in the retina. To increase its bioavailability, curcumin can be encapsulated in liposomes [44]; and that could allow the use of higher concentration to possibly inhibit diabetic retinopathy. Although, due to tissue limitations, direct measurements of curcumin levels in the retina were not made, the beneficial effects of curcumin observed in our study imply that curcumin was able to cross the blood-retina barrier. This is supported by others showing that curcumin can cross the blood-brain barrier in mice, and brain curcumin levels achieved are comparable to the levels achieved in the plasma [45].

\section{Conclusion}

The pathogenesis of diabetic retinopathy is complex. Curcumin, a common food additive, has beneficial effects in experimental studies of the diseases that are characterized by increased oxidative stress and inflammatory reactions supporting its clinical use. Our studies are the first to show that curcumin can inhibit diabetes-induced retinal abnormalities that are postulated in the development of diabetic retinopathy. Thus, curcumin appears to be a useful adjunct therapy to possibly inhibit the development/progression of retinopathy, the sight threatening complication faced by diabetic patients.

\section{Acknowledgements}

Technical assistance of Divyesh Sarman is greatly appreciated. This study was supported in part by grants from the National Institutes of Health, Juvenile Diabetes Research Foundation, the Thomas Foundation, and Research to Prevent Blindness.

\section{References}

I. Robison WG, Tillis TN, Laver N, Kinoshita JH: Diabetes-related histopathologies of the rat retina prevented with an aldose reductase inhibitor. Exp Eye Res 1990, 50(4):355-366.

2. Xu GW, Yao QH, Weng QF, Su BL, Zhang X, Xiong JH: Study of urinary 8-hydroxydeoxyguanosine as a biomarker of oxidative DNA damage in diabetic nephropathy patients. J Pharm Biomed Anal 2004, 36(I): I01-104.

3. Baynes JW, Thrope SR: Role of oxidative stress in diabetic complications: A new perspective on an old paradigm. Diabetes 1999, 48(I): I-9.

4. Kowluru RA, Tang J, Kern TS: Abnormalities of retinal metabolism in diabetes and experimental galactosemia. VII. Effect of long-term administration of antioxidants on the development of retinopathy. Diabetes 200I, 50(8): I938-1945.

5. Stitt AW: The role of advanced glycation in the pathogenesis of diabetic retinopathy. Exp Mol Pathol 2003, 75(I):95-108.

6. Kowluru RA, Kern TS, Engerman RL: Abnormalities of retinal metabolism in diabetes or experimental galactosemia. IV. Antioxidant defense system. Free Rad Biol Med 1997, 22(4):587-592.

7. Du Y, Miller CM, Kern TS: Hyperglycemia increases mitochondrial superoxide in retina and retinal cells. Free Rad Bio Med 2003, 35(I I): |49|-|499. 
8. Kowluru RA, Atasi L, Ho YS: Role of mitochondrial superoxide dismutase in the development of diabetic retinopathy. Invest Ophthal Vis Sci 2006, 47(4): $1594-1599$.

9. Brownlee M: Biochemistry and molecular cell biology of diabetic complications. Nature 200I, 4| 4(6865):8I3-820.

10. Joussen AM, Murata T, Tsujikawa A, Kirchhof B, Bursell SE, Adamis AP: Leukocyte-mediated endothelial cell injury and death in the diabetic retina. Am J Pathol 200I, I 58(I): I 47-I52.

II. Carmo A, Cunha-Vaz JG, Carvalho AP, Lopes MC: L-arginine transport in retinas from streptozotocin diabetic rats: correlation with the level of IL-I beta and NO synthase activity. Vision Res 1999, 39(23):3817-3823.

12. Kowluru RA, Odenbach S: Role of interleukin-lbeta in the development of retinopathy in rats: effect of antioxidants. Inves Ophthal Vis Sci 2004, 45(Ii):4I6I-4I66.

13. Kowluru RA, Odenbach S: Role of interleukin-Ibeta in the pathogenesis of diabetic retinopathy. British J Ophthalmol 2004, 88(10): | 343-| 347.

14. Fan F, Stoeltzing O, Liu W, McCarty MF, Jung YD, Reinmuth N, Ellis LM: Interleukin-I beta regulates angiopoietin-I expression in human endothelial cells. Cancer Res 2004, 64(9):3।86-3190.

15. Aiello LP: Angiogenic pathways in diabetic retinopathy. $N$ Engl J Med 2005, 353(8):839-84I.

16. Aggarwal BB, Shishodia S: Molecular targets of dietary agents for prevention and therapy of cancer. Biochem Pharmacol 2006 $7|(10):| 397-42 \mid$.

17. Hsuuw YD, Chang $\mathrm{CK}$, Chan WH, Yu JS: Curcumin prevents methylglyoxal-induced oxidative stress and apoptosis in mouse embryonic stem cells and blastocytes. I Cell Physio 2005, 205(3):379-386.

18. Strasser EM, Wessner B, Manhart N, Roth E: The relationship between the anti-inflammatory effects of curcumin and cellular glutathione content in myelomonocytic cells. Biochem Pharmacol 2005, 70(4):552-559.

19. Osawa T, Kato Y: Protective role of antioxidative food factors in oxidative stress caused by hyperglycemia. Ann N Y Acad Sci 2005, 1043:440-45I.

20. Okamoto T, Yamagishi S, Inagaki $Y$, Amano S, Koga K, Abe R, Takeuchi M, Ohno S, Yoshimura A, Makita Z: Angiogenesis induced by advanced glycation end products and its prevention by cerivastatin. FASEB 2002, 16(14):1928-1930.

21. Kowluru RA, Kowluru V, Xiong Y, Ho YS: Overexpression of mitochondrial superoxide dismutase in mice protects the retina from diabetes-induced oxidative stress. Free Rad Biol Med 2006, 4I(8): II91-II96.

22. Kowluru RA, Odenbach S: Effect of long-term administration of alpha lipoic acid on retinal capillary cell death and the development of retinopathy in diabetic rats. Diabetes 2004, 53(I2):3233-3238.

23. Koracevic D, Koracevic G, Djordjevic V, Andrejevic S, Cosic V: Method for the measurement of antioxidant activity in human fluids. J Clin Pathol 200I, 54(5):356-36I.

24. Pandya U, Saini MK, Jin GF, Awasthi S, Godley BF, Awasthi YC: Dietary curcumin prevents ocular toxicity of naphthalene in rats. Toxicol Lett 2000, I I 5(3): 195-204.

25. Farhangkhoee H, Khan ZA, Chen S, Chakrabarti S: Differential effects of curcumin on vasoactive factors in the diabetic rat heart. Nutr Metab (Lond) 2006, 3:27

26. Wu G, Fang YZ, Yang S, Lupton JR, Turner ND: Glutathione metabolism and its implication for health. J Nutr 2004, 134(3):489-492.

27. Moustafa SA: Zinc might protect oxidative changes in the retina and pancreas at the early stage of diabetic rats. Toxicol Appl Pharmacol 2004, 20I(2): 149-155.

28. Piper JT, Singhal SS, Salameh MS, Torman RT, Awasthi YC, Awasthi S: Mechanisms of anticarcinogenic properties of curcumin: the effect of curcumin on glutathione linked detoxification enzymes in rat liver. Int J Biochem Cell Biol 1998, 30(4):445-456.

29. Kowluru RA, Koppolu P, Chakrabarti S, Chen S: Diabetes-induced activation of nuclear transcriptional factor in the retina, and its inhibition by antioxidants. Free Rad Research 2003, 37(9): $1169-1180$

30. Du Y, Smith MA, Miller CM, Kern TS: Diabetes-induced nitrative stress in the retina, and correction by aminoguanidine. J Neurochem 2002, 80(5):77|-779.
31. Nanji AA, Jokelainen K, Tipoe GL, Rahemtulla A, Thomas P, Dannenberg AJ: Curcumin prevents alcohol-induced liver disease in rats by inhibiting the expression of NF-kappa B-dependent genes. Am J Physiol Gastrointest Liver Physiol 2003, 284(2):G32I-G327.

32. Thiyagarajan M, Sharma SS: Neuroprotective effect of curcumin in middle cerebral artery occlusion induced focal cerebral ischemia in rats. Life Sci 2004, 74(8):969-985

33. Joussen AM, Poulaki V, Le ML, Koizumi K, Esser C, Janicki H, Schraermeyer U, Kociok N, Fauser S, Kirchhof B, Kern TS, Adamis AP: A central role for inflammation in the pathogenesis of diabetic retinopathy. FASEB / 2004, I 8( I 2): | 450-1452.

34. Gerhardinger C, Costa MB, Coulombe MC, Toth I, Hoehn T, Grosu $P$ : Expression of acute-phase response proteins in retinal Muller cells in diabetes. Invest Ophthalmol Vis Sci 2005, 46(I):349-357.

35. Chang CK, LoCicero J: Overexpressed nuclear factor [kappa]B correlates with enhanced expression of interleukin-I [beta] and inducible nitric oxide synthase in aged murine lungs to endotoxic stress. The Ann Thor Surg 2004, 77(4): | 222-I 227.

36. Rahman I, MacNee W: Regulation of redox glutathione levels and genes transcription in lung inflammation: therpeutic approaches. Free Radic Biol Med 2000, 28(9): I 405-I 420.

37. Aggarwal BB, Shishodia S: Suppression of the nuclear factor-kappaB activation pathway by spice-derived phytochemicals: reasoning for seasoning. Ann NY Acad Sci 2004, I030:434-44I.

38. Romeo G, Liu WH, Asnaghi V, Kern TS, Lorenzi M: Activation of nuclear factor-kappaB induced by diabetes and high glucose regulates a proapoptotic program in retinal pericytes. Diabetes 2002, 5 I (7):224I-2248.

39. Kern TS, Tang J, Mizutani M, Kowluru R, Nagraj R, Lorenzi M Response of capillary cell death to aminoguanidine predicts the development of retinopathy: Comparison of diabetes and galactosemia. Invest Ophthalmol Vis Sci 2000, 4I( I 2):3972-3978

40. Obrosova IG, Minchenko AG, Marinescu V, Fathallah L, Kennedy A, Stockert CM, Frank RN, Stevens MJ: Antioxidants attenuate early up regulation of retinal vascular endothelial growth factor in streptozotocin-diabetic rats. Diabetologia 200I, 44(9): $1102-1110$.

4I. Cho ML, Jung YO, Moon YM, Min SY, Yoon CH, Lee SH, Park SH, Cho CS, Kim HY: Interleukin- 18 induces the production of vascular endothelial growth factor (VEGF) in rheumatoid arthritis synovial fibroblasts via AP-I-dependent pathways. Immunol Letters 2006, 103(2):159-166.

42. Chainani-Wu N: Safety and anti-inflammatory activity of curcumin: a component of tumeric (Curcuma longa). J Altern Complement Med 2003, 9(I):161-168.

43. Sharma RA, Gescher AJ, Steward WP: Curcumin: The story so far. Eur J Cancer 2005, 4 I ( I 3): 1955- I 968.

44. Li L, Braiteh FS, Kurzrock R: Liposome-encapsulated curcumin: in vitro and in vivo effects on proliferation, apoptosis, signaling, and angiogenesis. Cancer 2005, I04(6): | 322-133|.

45. Yang F, Lim GP, Begum AN, Ubeda OJ, Simmons MR, Ambegaokar SS, Chen PP, Kayed R, Glabe CG, Frautschy SA, Cole GM: Curcumin inhibits formation of amyloid beta oligomers and fibrils, binds plaques, and reduces amyloid in vivo. J Biol Chem 2005, 280(7):5892-5901.

Publish with Bio Med Central and every scientist can read your work free of charge

"BioMed Central will be the most significant development for disseminating the results of biomedical research in our lifetime. "

Sir Paul Nurse, Cancer Research UK

Your research papers will be:

- available free of charge to the entire biomedical community

- peer reviewed and published immediately upon acceptance

- cited in PubMed and archived on PubMed Central

- yours - you keep the copyright 